\title{
Does Surface Topography Play a Role in Taper Damage in Head-neck Modular Junctions?
}

\author{
Robin Pourzal PhD, Deborah J. Hall BS, Nguyen Q. Ha BA, \\ Robert M. Urban, Brett R. Levine MD, Joshua J. Jacobs MD, \\ Hannah J. Lundberg PhD
}

Published online: 23 June 2016

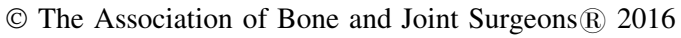

\begin{abstract}
Background There are increasing reports of total hip arthroplasty failure subsequent to modular taper junction corrosion. The surfaces of tapers are machined to have circumferential machining marks, resulting in a surface topography of alternating peaks and valleys on the scale of micrometers. It is unclear if the geometry of this machined surface topography influences the degree of fretting and corrosion damage present on modular taper junctions or if there are differences between modular taper junction material couples.

Questions/purposes (1) What are the differences in damage score and surface topography between $\mathrm{CoCr} / \mathrm{CoCr}$

The institution has received money from the National Institutes of Health (R03 AR066829; HJL), the Rush Translational Sciences Consortium (RTSC; RP), and the Rush Arthritis and Orthopedic Institute (DJH, RMU). Statistical support was provided by the Center for Clinical and Translational Science, University of Illinois at Chicago, through funding from the National Institutes of Health (UL1TR000050) and the Rush Research Mentoring Program. All ICMJE Conflict of Interest Forms for authors and Clinical Orthopaedics and Related Research $\mathbb{R}$ editors and board members are on file with the publication and can be viewed on request.

Clinical Orthopaedics and Related Research $\mathbb{R}$ neither advocates nor endorses the use of any treatment, drug, or device. Readers are encouraged to always seek additional information, including FDAapproval status, of any drug or device prior to clinical use.

Each author certifies that his or her institution approved the human protocol for this investigation, that all investigations were conducted in conformity with ethical principles of research, and that informed consent for participation in the study was obtained.
\end{abstract}

R. Pourzal ( $₫)$, D. J. Hall, N. Q. Ha, R. M. Urban, B. R. Levine, J. J. Jacobs, H. J. Lundberg

Department of Orthopedic Surgery, Rush University Medical Center, 1611W Harrison Street, Suite 200, Chicago, IL 60612, USA

e-mail: Robin_Pourzal@rush.edu and $\mathrm{CoCr} / \mathrm{Ti}$ modular junctions? (2) How are initial surface topography, flexural rigidity, taper angle mismatch, and time in situ related to visual taper damage scores for $\mathrm{CoCr} /$ CoCr couples? (3) How are initial surface topography, flexural rigidity, taper angle mismatch, and time in situ related to visual taper damage scores for $\mathrm{CoCr} / \mathrm{Ti}$ couples? Methods Damage on stem and head tapers was evaluated with a modified Goldberg score. Differences in damage scores were determined between a group of $140 \mathrm{CoCr} /$ $\mathrm{CoCr}$ couples and $129 \mathrm{CoCr} / \mathrm{Ti}$ couples using a chi-square test. For a subgroup of 70 retrievals, selected at random, we measured five variables, including initial stem taper machining mark height and spacing, initial head taper roughness, flexural rigidity, and taper angle mismatch. All retrievals were obtained at revision surgeries. None were retrieved as a result of metal-on-metal failures or were recalled implants. Components were chosen so there was a comparable number of each material couple and damage score. Machining marks around the circumference of the tapers were measured using white light interferometry to characterize the initial stem taper surface topography in terms of the height of and spacing between machining mark peaks as well as initial head taper roughness. The taper angle mismatch was assessed with a coordinate measuring machine. Flexural rigidity was determined based on measurements of gross taper dimensions and material properties. Differences of median or mean values of all variables between material couples were determined (Wilcoxon rank-sum tests and t-tests). The effect of all five variables along with time in situ on stem and head taper damage scores was tested with a multiple regression model. With 70 retrievals, a statistical power of 0.8 could be achieved for the model.

Results Damage scores were different between $\mathrm{CoCr} /$ $\mathrm{CoCr}$ and $\mathrm{CoCr} / \mathrm{Ti}$ modular taper junction material couples. 
$\mathrm{CoCr} / \mathrm{CoCr}$ stem tapers were less likely to be mildly damaged $(11 \%, \mathrm{p}=0.006)$ but more likely to be severely damaged $(4 \%, \mathrm{p}=0.02)$ than $\mathrm{CoCr} / \mathrm{Ti}$ stem tapers $(28 \%$ and $1 \%$, respectively). $\mathrm{CoCr} / \mathrm{CoCr}$ couples were less likely to have moderately worn head tapers (7\% versus $17 \%$, $\mathrm{p}=0.003)$. Stem taper machining mark height and spacing and head taper roughness were 11 (SD 3), 185 (SD 46), and 0.57 (SD 0.5) for $\mathrm{CoCr} / \mathrm{CoCr}$ couples and 10 (SD 3), 170 (SD 56), and 0.64 (SD 0.4) for $\mathrm{CoCr} / \mathrm{Ti}$ couples, respectively. There was no difference $(\mathrm{p}=0.09, \mathrm{p}=0.1$, $\mathrm{p}=0.16$, respectively) for either factor between material couples. Larger stem taper machining mark heights ( $p=0.001)$ were associated with lower stem taper damage scores, and time in situ $(\mathrm{p}=0.006)$ was associated with higher stem taper damage scores for $\mathrm{CoCr} / \mathrm{CoCr}$ material couples. Stem taper machining marks that had higher peaks resulted in slower damage progression over time. For $\mathrm{CoCr} / \mathrm{Ti}$ material couples, head taper roughness was associated with higher stem $(\mathrm{p}=0.001)$ and head taper $(\mathrm{p}=0.003)$ damage scores, and stem taper machining mark height, but not time in situ, was associated with lower stem taper damage scores $(\mathrm{p}=0.007)$.

Conclusions Stem taper surface topography was related to damage scores on retrieved head-neck modular junctions; however, it affected $\mathrm{CoCr} / \mathrm{CoCr}$ and $\mathrm{CoCr} / \mathrm{Ti}$ couples differently.

Clinical Relevance A taper topography of circumferential machining marks with higher peaks appears to enable slower damage progression and, subsequently, a reduction of the reported release of corrosion products. This may be of interest to implant designers and manufacturers in an effort to reduce the effects of metal release from modular femoral components.

\section{Introduction}

Although modularity of THAs has been around for decades, reports of modular head-neck junction corrosion and metal release continue to rise. Corrosion products can trigger adverse local tissue reactions (ALTRs) and subsequent revision surgery. Multiple case reports have implicated corrosion of modular head-neck junctions as the cause of hip pain resulting in revision surgery $[2,26,28,29,33,37,38]$. So far the largest clinical series have suggested that between $1.8 \%$ and $2.3 \%$ of patients undergoing THA with metal-on-polyethylene bearings will undergo revision surgery per year because of modular head-neck junction corrosion $[9,10]$. This number may be underreported because it can masquerade as infection and instability. Even for reports of metal-on-metal bearing failure, the head-neck modular junction has been associated with high metal ion release [13, 22, 24, 36].
Factors previously identified as increasing corrosion and fretting of modular head-neck junctions include design characteristics such as larger femoral head diameter [5, 12], longer femoral neck offset $[4,11,16,25]$, larger angular mismatch between the stem taper and head taper [2, 6], and higher flexural rigidity [17]. Surgical assembly technique such as the force and angle at which the surgeon impacts the femoral head onto the stem taper [32] and the presence of fluid or debris on the taper surfaces during surgical assembly $[16,21]$ can negatively affect the taper's initial stability. Material alloy of the head and stem taper also plays a role because different corrosion and fretting processes can occur depending on the material couple $[18,19]$.

One aspect that has received little attention is the surface topography of the head and stem taper surfaces. The taper surfaces have parallel machining lines, which create a rough surface meant to provide for strong interlocking between the femoral head and stem during assembly in the operating room. We previously characterized the stem taper surface topography as a wave defined by height and spacing parameters (Fig. 1A) and found that the surface topography of stem tapers was highly variable depending on the manufacturer and material alloy used for the femoral stem [27]. The most frequently used stem/head taper metal alloy couples are either a CoCrMo or a Ti6Al4 V stem paired with a CoCrMo head $(\mathrm{CoCr} / \mathrm{CoCr}$ and $\mathrm{CoCr} / \mathrm{Ti}$, respectively). So far, it is unclear how taper surface topography influences the degree of damage on the taper surfaces and if the influence is mitigated or enhanced by

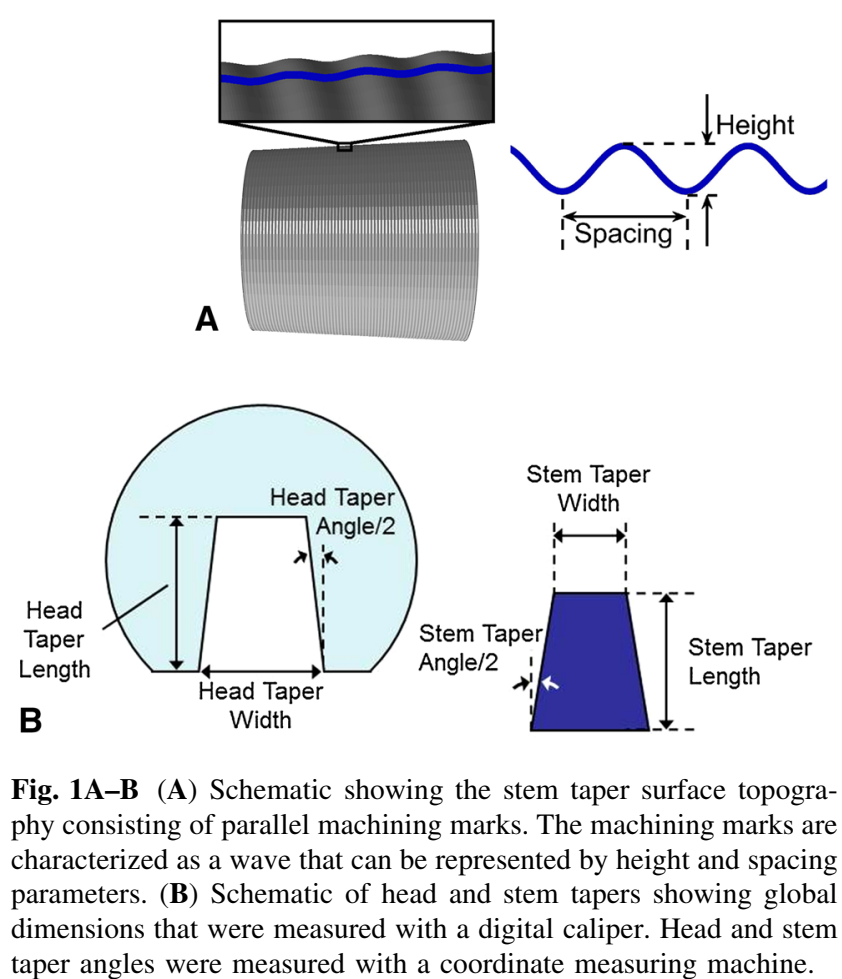


Table 1. Retrieval demographics $(\mathrm{n}=70)$

\begin{tabular}{|c|c|}
\hline Retrieval characteristic & Number \\
\hline \multicolumn{2}{|l|}{ Reason for revision } \\
\hline Septic loosening & 32 \\
\hline Aseptic loosening & 23 \\
\hline Periprosthetic fracture & 7 \\
\hline Stem loosening and lysis & 2 \\
\hline Stem subsidence & 1 \\
\hline Unknown & 5 \\
\hline \multicolumn{2}{|l|}{ Head diameter $(\mathrm{mm})$} \\
\hline 28 & 20 \\
\hline 32 & 24 \\
\hline 36 & 17 \\
\hline 38 & 1 \\
\hline 40 & 3 \\
\hline 42 & 2 \\
\hline 46 & 1 \\
\hline 48 & 1 \\
\hline 50 & 1 \\
\hline \multicolumn{2}{|l|}{ Manufacturer } \\
\hline Zimmer (Warsaw, IN, USA) & 33 \\
\hline DePuy (Warsaw, IN, USA) & 15 \\
\hline Stryker (Mahwah, NJ, USA) & 2 \\
\hline $\begin{array}{l}\text { Wright Medical Technology (Memphis, } \\
\text { TN, USA) }\end{array}$ & 6 \\
\hline Smith \& Nephew (Memphis, TN, USA) & 6 \\
\hline Richards (Memphis, TN, USA) & 4 \\
\hline Howmedica (Rutherford, NJ, USA) & 1 \\
\hline Sulzer Medica (Winterthur, Switzerland) & 1 \\
\hline Biomet (Warsaw, IN, USA) & 1 \\
\hline LINK (Hamburg, Germany) & 1 \\
\hline \multicolumn{2}{|l|}{ Bearing surface } \\
\hline Metal-on-polyethylene & 59 \\
\hline Metal-on-metal & 6 \\
\hline Hemiarthroplasty & 5 \\
\hline \multicolumn{2}{|l|}{ Trunnion material } \\
\hline CoCr alloy & 37 \\
\hline Ti4Al6V alloy & 33 \\
\hline \multicolumn{2}{|l|}{ Nominal trunnion size } \\
\hline $12 / 14$ & 64 \\
\hline $14 / 16$ & 3 \\
\hline V40 ${ }^{\mathrm{TM}}$ (Stryker, Mahwah, NJ, USA) & 2 \\
\hline C-Taper & 1 \\
\hline
\end{tabular}

design factors such as flexural rigidity and taper angle mismatch, previously identified as important for head-neck taper corrosion.

Therefore, we analyzed taper surface topography characteristics, design features, and damage scores of retrieved THAs with either $\mathrm{CoCr} / \mathrm{CoCr}$ or $\mathrm{CoCr} / \mathrm{Ti}$ modular junctions. Specifically, we investigated the following three research questions: (1) What are the differences in damage score and surface topography between $\mathrm{CoCr} / \mathrm{CoCr}$ and $\mathrm{CoCr} / \mathrm{Ti}$ modular junctions? (2) How are initial surface topography, flexural rigidity, taper angle mismatch, and time in situ related to visual taper damage scores for $\mathrm{CoCr} /$ CoCr couples? (3) How are initial surface topography, flexural rigidity, taper angle mismatch, and time in situ related to visual taper damage scores for $\mathrm{CoCr} / \mathrm{Ti}$ couples?

\section{Materials and Methods}

We performed a retrospective analysis of retrievals in our institutional review board-approved implant registry. All implants were retrieved at revision surgery from 2004 to 2014 and implanted between 1995 and 2012. The registry contained 269 paired head and stem tapers of either $\mathrm{CoCr} /$ $\mathrm{CoCr}$ (140) or $\mathrm{CoCr} / \mathrm{Ti}$ (129) material couples (Table 1). The retrievals represented 11 manufacturers with the majority of the implants from Zimmer (Zimmer Inc, now Zimmer-Biomet, Warsaw, IN, USA). The bearing surfaces of the retrievals were metal-on-polyethylene $(\mathrm{N}=226)$, metal-on-metal $(\mathrm{N}=22)$, hemiarthroplasty $(\mathrm{N}=19)$, and two unknown. None were metal-on-metal failures or from recalled implant designs. All retrievals had CoCrMo heads.

The head and stem taper surfaces were scored using a stereo microscope (SMZ-U; Nikon, Melville, NY, USA) based on a validated visual damage scoring system (modified Goldberg score) [17, 35], where damage is scored from least to most severe as none (1), mild (2), moderate (3), or severe (4). The score included damage resulting from fretting and corrosion combined [9]. Two observers scored the surfaces (RMU, DJH). In the case of disagreement in scores between the two observers, the observers discussed and came to a consensus on the score. The reliability of this technique compared with volumetric measurements of material loss has been studied by Hothi et al. [20], who found an intraobserver and interobserver agreement of greater than $90 \%$. Head and stem taper scores were correlated with volumetric wear measurements, and the agreement was especially good for lower visual damage scores (1-3).

A subset of 70 THAs $(37 \mathrm{CoCr} / \mathrm{CoCr}, 33 \mathrm{CoCr} / \mathrm{Ti})$ was randomly chosen for the evaluation of the initial as-manufactured taper surface topography (Table 2). Components were chosen so there was a comparable number of head and stem damage scores for each material couple; however, components with severely damaged stem tapers (score 4) were excluded, because evaluation of the initial surface topography could not be ensured. For stem tapers, surface topography was defined by the height and spacing of the circumferential machining marks (Fig. 1A). A white light interferometer (NewView 6000; Zygo, Middlefield, CT, 
Table 2. Frequency of head and stem damage scores for the subgroups of $\mathrm{CoCr} / \mathrm{CoCr}$ and $\mathrm{CoCr} / \mathrm{Ti}$ couples selected for the evaluation of surface topography

\begin{tabular}{|c|c|c|c|c|c|c|c|c|}
\hline \multirow[t]{3}{*}{ Alloy couple } & \multicolumn{8}{|c|}{ Damage score } \\
\hline & \multicolumn{2}{|c|}{ None (1) } & \multicolumn{2}{|l|}{ Mild (2) } & \multicolumn{2}{|c|}{ Moderate (3) } & \multicolumn{2}{|c|}{ Severe (4) } \\
\hline & Number & Percent & Number & Percent & Number & Percent & Number & Percent \\
\hline $\mathrm{CoCr} / \mathrm{CoCr}$ (stem taper) & 18 & 49 & 8 & 22 & 11 & 30 & 0 & 0 \\
\hline $\mathrm{Ti} / \mathrm{CoCr}$ (stem taper) & 15 & 45 & 10 & 30 & 8 & 24 & 0 & 0 \\
\hline $\mathrm{CoCr} / \mathrm{CoCr}$ (head taper) & 25 & 68 & 5 & 14 & 3 & 8 & 4 & 11 \\
\hline $\mathrm{Ti} / \mathrm{CoCr}$ (head taper) & 21 & 64 & 6 & 18 & 2 & 6 & 4 & 12 \\
\hline
\end{tabular}

USA) was used to measure the stem taper surface topography. Imaging was conducted at $\times 400$ over an evaluation length of $700 \mu \mathrm{m}$. At this magnification, damaged machining mark peaks could easily be identified and avoided to ensure that only the initial as-manufactured surface topography was evaluated. Six images were collected: three around the circumference of the proximal stem taper and three around the circumference of the distal stem taper. Linear profiles were taken perpendicular to the machining marks through each image. Custom-written Matlab software (The Mathworks Inc, Natick, MA, USA) was used to identify the height and spacing between machining marks as previously described [27]. Preliminary investigations revealed that the head taper surfaces did not have consistent machining mark topography; therefore, average surface roughness $\left(R_{a}\right)$ was used to define the head taper surface topography [27]. For this study, femoral heads could not be sectioned, which made surface evaluation by white light interferometry impossible. Therefore, the roughness of the head taper surfaces was measured with a tactile profilometer (Surftest SJ201P; Mitutoyo, Aurora, IL, USA). Great care was taken to avoid areas of visible damage.

In addition to the evaluation of surface topography, design factors were measured including taper angle mismatch and head and stem taper width and length (Fig. 1B). A coordinate measuring machine (Smartscope; OGP, Rochester, NY, USA) in tactile mode with a 2-mm diameter ruby ball was used to determine the head and stem taper angles. Fifteen points were collected in areas optically free from damage in three planes (proximal, center, and distal) perpendicular to the axis of the head and stem tapers. The exact locations of the points were chosen to avoid areas with visible damage. A perfect cone was fitted to the points to compute the taper angle. Head and stem taper angles were defined as the angle of the cone; taper angle mismatch was defined as the head taper angle minus the stem taper angle. Flexural rigidity was calculated as the elastic modulus of the stem taper times the bending moment of inertia about the centroid of the stem taper [31] using the stem taper width and length. These taper dimensions were measured with a digital caliper (Fig. 1B).

Both semiquantitative and quantitative measures were used to address the three research questions. Damage scores for the stem and head taper surfaces were semiquantitative. The height and spacing of stem taper surface topographies, average roughness of head tapers, flexural rigidity of stem tapers, and angular mismatch between the stem and head tapers were quantitative. Another quantitative variable, time in situ, was also reported because it could be a confounding factor that influenced damage score.

To answer research question 1 , a chi-square test was used to compare the frequency of damage scores within different material couples for the entire retrieval group. With a sample size of 269 retrievals, we achieved a power of 0.95 to detect an effect size (W) of 0.25 with a significance level of 0.05 . For the analyzed subgroups of each material couple damage score, machining mark height and spacing, head taper roughness, flexural rigidity, and time in situ were compared using the Wilcoxon rank-sum test. Differences in taper angle mismatch were tested with a two-tailed t-test. The significance level for comparisons was set as $p=0.05$. For comparing the two groups, our random sample of 70 implants could detect an effect size (difference of means divided by the SD) of 0.7 with a power level of 0.8 at a confidence level of $95 \%$. To answer research questions 2 and 3, for each material couple group, the effect of the six quantitative variables on head and stem taper damage scores was evaluated using a multiple regression model (SPSS, IBM Corp, Armonk, NY, USA). Only significant variables $(p<0.05)$ remained in the model. Normality of the data was confirmed by qq-plots. Our random sample of 70 implants could detect slopes of 0.01 per month for time in situ, $0.14 \mu \mathrm{m}^{-1}$ for stem machining mark height, $0.01 \mu^{-1}$ stem machining mark spacing, and $0.9 \mu \mathrm{m}^{-1}$ for head roughness with a power level of 0.8 at a confidence level of $95 \%$. 


\section{Results}

With the numbers available, there were no differences in damage scores, surface topography, flexural rigidity, or taper angle mismatch between $\mathrm{CoCr} / \mathrm{CoCr}$ and $\mathrm{CoCr} / \mathrm{Ti}$ modular junctions. For all couples in our implant registry, the mean damage scores for the stem and head tapers were $1.8 \pm 0.9 \mathrm{SD}$ and $1.7 \pm 1 \mathrm{SD}$ for $\mathrm{CoCr} / \mathrm{CoCr}$ couples and $1.8 \pm 0.8 \mathrm{SD}$ and $1.7 \pm 1 \mathrm{SD}$ for $\mathrm{CoCr} / \mathrm{Ti}$ couples, respectively. No damage (score 1) was the most common score for both $\mathrm{CoCr} / \mathrm{CoCr}$ and $\mathrm{CoCr} / \mathrm{Ti}$ couples for stem (73\% and 60\%; Fig. 2) and head tapers (74\% and 63\%; Fig. 3). $\mathrm{CoCr} / \mathrm{CoCr}$ couples were more likely $(\mathrm{p}=0.02)$ to have severely damaged (score 4) stem tapers $(6 \%)$ than $\mathrm{CoCr} / \mathrm{Ti}$ couples $(1 \%)$ and less likely $(\mathrm{p}=0.006)$ to have

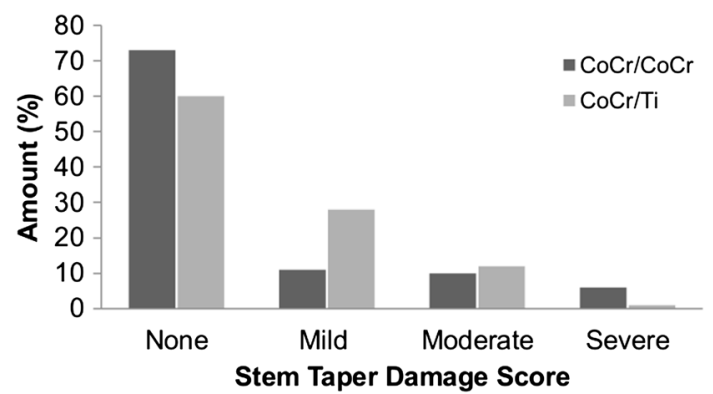

Fig. 2 Distribution of stem taper damage scores shown for $\mathrm{CoCr} /$ $\mathrm{CoCr}$ and $\mathrm{CoCr} / \mathrm{Ti}$ couples.

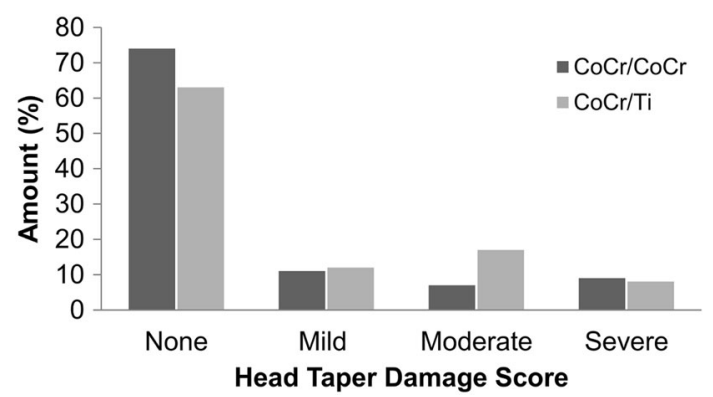

Fig. 3 Distribution of head taper damage scores shown for $\mathrm{CoCr} /$ $\mathrm{CoCr}$ and $\mathrm{CoCr} / \mathrm{Ti}$ couples. mildly damaged (score 2) stem tapers (Table 3). The percentage of severely damaged (score 4 ) head tapers was not different at $9 \%$ and $8 \%$ for $\mathrm{CoCr} / \mathrm{CoCr}$ and $\mathrm{CoCr} / \mathrm{Ti}$ couples, respectively (Table 4). However, the $\mathrm{CoCr} / \mathrm{Ti}$ coupled head tapers exhibited a higher number of moderately damaged (score 3 ) tapers than $\mathrm{CoCr} / \mathrm{CoCr}$ couples $(17 \%$ versus $7 \%$, respectively; $\mathrm{p}=0.003$ ).

The median machining mark height were spacing on the stem tapers for the subgroup of $37 \mathrm{CoCr} / \mathrm{CoCr}$ couples was 11 (range, 1.6-14) $\mu \mathrm{m}$ and 200 (range, 24-229) $\mu \mathrm{m}$, respectively (Table 5). The median machining mark height and spacing on the stem tapers for the subgroup of 33 $\mathrm{CoCr} / \mathrm{Ti}$ couples were 11 (range, 1.9-13) $\mu \mathrm{m}$ and 198 (range, 30-234) $\mu \mathrm{m}$, respectively (Table 5). There were no differences between material couples for either stem taper machining mark height (Fig. 4) or spacing (Fig. 5). The topography of the head tapers did not follow a repeating pattern of machining marks in $24 \%(\mathrm{CoCr} / \mathrm{CoCr})$ and $22 \%$ ( $\mathrm{CoCr} / \mathrm{Ti})$ of cases. Therefore, topography was quantified by means of $R_{a}$ instead of machining mark characteristics. The median $\mathrm{R}_{\mathrm{a}}$ was 0.50 (range, 0.14-2.2) $\mu \mathrm{m}$ for $\mathrm{CoCr} /$ CoCr couples and 0.65 (range, 0.24-1.8) $\mu \mathrm{m}$ for $\mathrm{CoCr} / \mathrm{Ti}$ couples. The median flexural rigidity was 365 (range, 230581) $\mathrm{Nm}^{2}$ for $\mathrm{CoCr} / \mathrm{CoCr}$ couples and 177 (range, 117265) $\mathrm{Nm}^{2}$ for $\mathrm{CoCr} / \mathrm{Ti}$ couples (Table 5). The mean taper angle mismatch between the head and stem taper was $0.05^{\circ}$ (SD $0.1 ; 95 \%$ confidence interval [CI], 0.1-0.8) for $\mathrm{CoCr} /$ $\mathrm{CoCr}$ and $0.03^{\circ}$ (SD 0.1; 95\% CI, -0.2-0.8) for $\mathrm{CoCr} / \mathrm{Ti}$ couples. There was no significant difference in taper angle mismatch between material couples $(\mathrm{p}=0.6)$.

For $\mathrm{CoCr} / \mathrm{CoCr}$ stem tapers, machining mark height and time in situ were associated with higher damage scores, but for $\mathrm{CoCr} / \mathrm{CoCr}$ head tapers, only stem taper machining mark height was associated with higher damage scores. For stem tapers, the multiple regression had an improved outcome by replacing time in situ with an interaction term between machining mark height and time in situ. The resulting relationship between the two factors showed that a higher machining mark height slows damage score increase over time, whereas a shallower stem taper topography results in a steep initial increase in damage score followed by only a

Table 3. Frequency of stem taper damage scores for $\mathrm{CoCr} / \mathrm{CoCr}$ and $\mathrm{CoCr} / \mathrm{Ti}$ couples

\begin{tabular}{|c|c|c|c|c|c|c|c|c|}
\hline \multirow[t]{3}{*}{ Alloy couple } & \multicolumn{8}{|l|}{ Damage score } \\
\hline & \multicolumn{2}{|l|}{ None (1) } & \multicolumn{2}{|l|}{ Mild (2) } & \multicolumn{2}{|l|}{ Moderate (3) } & \multicolumn{2}{|l|}{ Severe (4) } \\
\hline & Amount & $\begin{array}{l}\text { Time } \\
\text { in situ } \\
\text { (years) }\end{array}$ & Amount & $\begin{array}{l}\text { Time } \\
\text { in situ } \\
\text { (years) }\end{array}$ & Amount & $\begin{array}{l}\text { Time } \\
\text { in situ } \\
\text { (years) }\end{array}$ & Amount & $\begin{array}{l}\text { Time } \\
\text { in situ } \\
\text { (years) }\end{array}$ \\
\hline $\mathrm{CoCr} / \mathrm{CoCr}$ & $73 \%(\mathrm{~N}=102)$ & 4.8 & $11 \%(\mathrm{~N}=16)$ & 5 & $10 \%(\mathrm{~N}=14)$ & 7 & $6 \%(\mathrm{~N}=8)$ & 6.2 \\
\hline $\mathrm{Ti} / \mathrm{CoCr}$ & $60 \%(\mathrm{~N}=77)$ & 1.8 & $28 \%(\mathrm{~N}=36)$ & 2.1 & $12 \%(\mathrm{~N}=15)$ & 1.9 & $1 \%(\mathrm{~N}=1)$ & 0.6 \\
\hline $\mathrm{p}$ value & 0.062 & 0.25 & 0.006 & 0.28 & 0.85 & 0.09 & 0.02 & 0.03 \\
\hline
\end{tabular}


Table 4. Frequency of head taper damage scores for $\mathrm{CoCr} / \mathrm{CoCr}$ and $\mathrm{CoCr} / \mathrm{Ti}$ couples

\begin{tabular}{|c|c|c|c|c|c|c|c|c|}
\hline \multirow[t]{3}{*}{ Alloy couple } & \multicolumn{8}{|l|}{ Damage score } \\
\hline & \multicolumn{2}{|l|}{ None (1) } & \multicolumn{2}{|l|}{ Mild (2) } & \multicolumn{2}{|l|}{ Moderate (3) } & \multicolumn{2}{|l|}{ Severe (4) } \\
\hline & Amount & $\begin{array}{l}\text { Time in } \\
\text { situ (years) }\end{array}$ & Amount & $\begin{array}{l}\text { Time in } \\
\text { situ (years) }\end{array}$ & Amount & $\begin{array}{l}\text { Time in } \\
\text { situ (years) }\end{array}$ & Amount & $\begin{array}{l}\text { Time in } \\
\text { situ (years) }\end{array}$ \\
\hline $\mathrm{CoCr} / \mathrm{CoCr}$ & $74 \%(\mathrm{~N}=103)$ & 4.9 & $11 \%(\mathrm{~N}=15)$ & 6.2 & $7 \%(\mathrm{~N}=10)$ & 3.9 & $9 \%(\mathrm{~N}=12)$ & 6.2 \\
\hline $\mathrm{Ti} / \mathrm{CoCr}$ & $63 \%(\mathrm{~N}=81)$ & 1.8 & $12 \%(\mathrm{~N}=16)$ & 2.1 & $17 \%(\mathrm{~N}=22)$ & 1.8 & $8 \%(\mathrm{~N}=10)$ & 3.5 \\
\hline $\mathrm{p}$ value & 0.11 & 0.23 & 0.86 & 0.067 & 0.003 & 0.38 & 0.67 & 0.39 \\
\hline
\end{tabular}

Table 5. Time in situ, damage scores, and design factors for $\mathrm{CoCr} / \mathrm{CoCr}$ and $\mathrm{CoCr} / \mathrm{Ti}$ couples*

\begin{tabular}{llllllllll}
\hline $\begin{array}{l}\text { Alloy } \\
\text { couple }\end{array}$ & $\begin{array}{l}\text { Number } \\
\text { in situ } \\
(\text { months })\end{array}$ & $\begin{array}{l}\text { Time } \\
\text { score }\end{array}$ & $\begin{array}{l}\text { Stem taper } \\
\text { samage }\end{array}$ & $\begin{array}{l}\text { Head taper } \\
\text { damage }\end{array}$ & $\begin{array}{l}\text { Flexural } \\
\text { rigidity } \\
\left(\mathrm{Nm}^{2}\right)\end{array}$ & $\begin{array}{l}\text { Taper angle } \\
\text { mismatch } \\
\left({ }^{\circ}\right)\end{array}$ & $\begin{array}{l}\text { Stem taper } \\
\text { machining mark } \\
\text { height }(\mu \mathrm{m})\end{array}$ & $\begin{array}{l}\text { Stem taper } \\
\text { machining mark } \\
\text { spacing }(\mu \mathrm{m})\end{array}$ & $\begin{array}{l}\text { Head taper } \\
\text { roughness } \\
\left(\mathrm{R}_{\mathrm{a}} ; \mu \mathrm{m}\right)\end{array}$ \\
\hline $\mathrm{CoCr} / \mathrm{CoCr}$ & 37 & $31(0-122)$ & $2(1-3)$ & $1(1-4)$ & $365(230-581)$ & $0.05(\mathrm{SD} 0.1)$ & $11(1.6-14)$ & $200(24-229)$ & $0.5(0.14-2.2)$ \\
$\mathrm{Ti} / \mathrm{CoCr}$ & 33 & $13(0.6-136)$ & $2(1-3)$ & $1(1-4)$ & $177(117-265)$ & $0.03(\mathrm{SD} 0.1)$ & $11(1.9-13)$ & $198(30-234)$ & $0.65(0.24-1.8)$ \\
$\mathrm{p}$ value & 0.63 & 0.29 & 0.97 & 0.96 & $<0.001$ & 0.58 & 0.09 & 0.1 & 0.16 \\
\hline
\end{tabular}

*All numbers are reported as median (range) except for taper angle mismatch, which is reported as mean (SD).

marginal increase over time (Fig. 6). At approximately 10 years in situ, the damage score became independent of the topography. For the head tapers, stem taper machining mark height was associated with higher damage scores $(p=0.001)$ (Fig. 7), but time in situ was not $(p=0.441)$. The difference was especially pronounced between mild and moderate damage, where higher stem taper machining marks resulted in a lower head taper damage score.

For $\mathrm{CoCr} / \mathrm{Ti}$ couples, the only factors associated with stem taper damage were head taper roughness and the stem taper machining mark height, whereas only head taper roughness was associated with head taper damage. There appeared to be a pronounced difference in damage score for flexural rigidity (Fig. 8) and head taper roughness (Fig. 9) between mild and moderate damage. However, the multiple regression model that controlled for all factors revealed only the head taper roughness $(p=0.001)$ and stem taper machining mark height $(\mathrm{p}=0.007)$ were associated with stem taper damage score. Increasing stem taper machining mark height correlated with a decrease in stem taper damage score and increasing head taper roughness correlated with an increase in stem taper damage score. Head taper roughness was also associated with higher head taper damage scores $(\mathrm{p}=0.003)$ by multiple regression.

\section{Discussion}

Success of THAs can be limited by ALTRs triggered by corrosion products generated in the modular taper junction.
Surface damage caused by corrosion processes is a multifactorial problem, which includes several design, material factors, and patient and surgical factors. We sought to determine whether surface topography applied to the stem and head taper surfaces plays a role in the damage process. Our results suggest that especially the machining mark characteristics on the stem taper contribute to the visual damage outcome of the head and stem tapers. Stem taper topography is most impactful in $\mathrm{CoCr} / \mathrm{CoCr}$ couples.

This study has several limitations including (1) limitations associated with the repository from which the retrievals were drawn; (2) limitations of the retrieval sample $(\mathrm{n}=70)$ reported; and (3) methodological limitations. The larger repository from which the retrievals were drawn has a large representation from one manufacturer, Zimmer (Warsaw, IN, USA), as a result of the use of those particular implants at Rush. Nevertheless, 10 manufacturers were represented in the 70 retrievals evaluated in this study. The retrievals in the repository were all obtained at the time of revision surgery and were not removed as a result of taper corrosion, but for various other reasons (Table 1). Therefore, we are investigating taper topography simply as an indicator of damage accumulation. There are several limitations regarding the subgroup of 70 retrievals, which include the obtained statistical power, the exclusion of severely damaged stem tapers, the low number of retrievals with long in situ times, and the fact that patient weight and implant alignment were not available. With 70 retrievals, this study had a power of $80 \%$ to detect a true difference. Further studies need to be conducted with a larger sample size to achieve higher power. We did not 


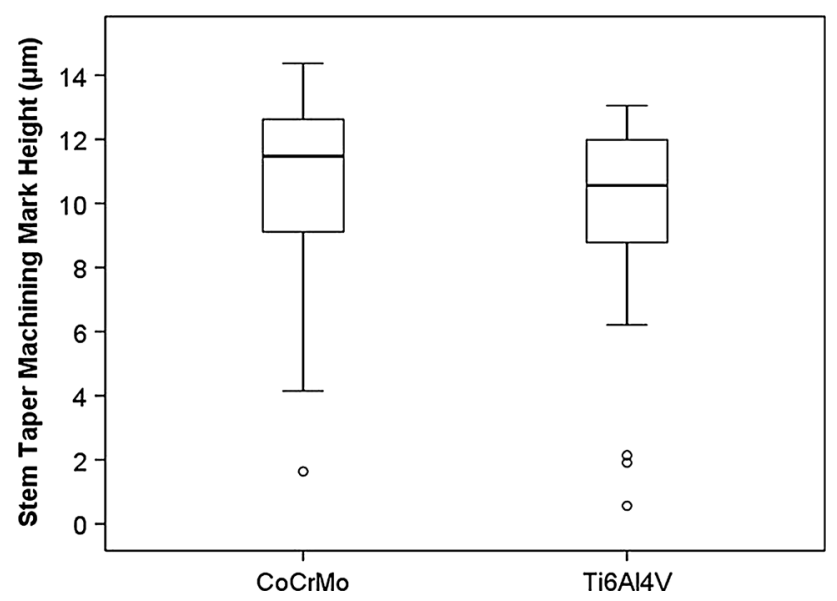

Fig. 4 Comparison showing stem taper machining mark height for $\mathrm{CoCr} / \mathrm{CoCr}$ and $\mathrm{CoCr} / \mathrm{Ti}$ couples. Circles mark mild outliers (between $1.5 \times \mathrm{q}$ to $3 \times \mathrm{q}$ away from the nearest quartile; $\mathrm{q}=$ interquartile range).

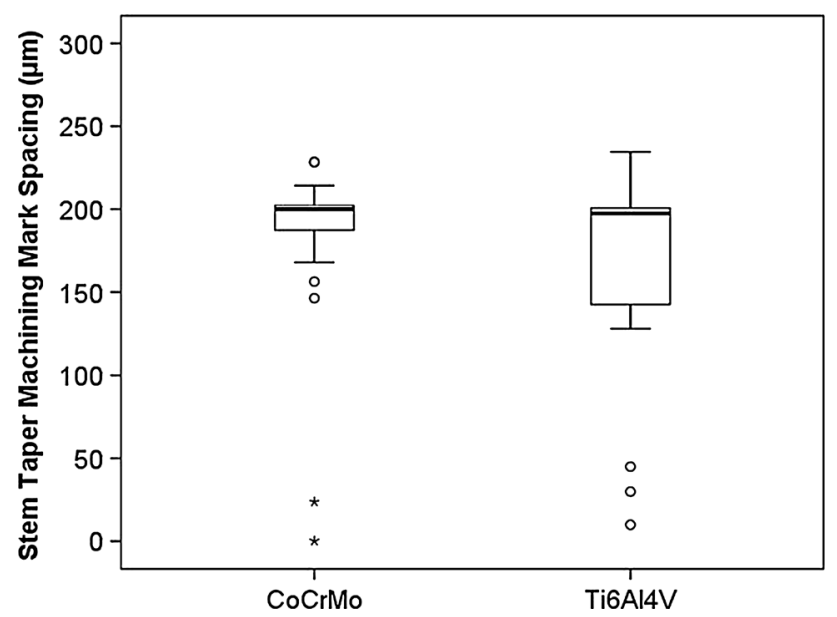

Fig. 5 Comparison of stem taper machining mark spacing for $\mathrm{CoCr} /$ $\mathrm{CoCr}$ and $\mathrm{CoCr} / \mathrm{Ti}$ couples is shown. Circles mark mild outliers and asterisks mark extreme outliers $(>3 \times \mathrm{q}$ away from the nearest outlier).

evaluate stem tapers categorized as "severely" damaged (score 4) as a result of the low numbers present in the repository. Stem tapers of score 4 only constituted $6 \%$ of the CoCrMo stem tapers and $1 \%$ of the Ti6Al4 V stem tapers in the entire retrieval repository. Additionally, it was not possible to accurately determine the initial surface topography for those components as a result of the excessive amount of corrosion damage. Knowledge of the initial stem taper topography was required for the inclusion as an input variable to the regression model. Only three retrievals had in situ times greater than 10 years. Retrievals with longer in situ times should be added to the model as they become available to determine definitively if specific surface topography characteristics result in implants that last longer in vivo. We also recognize that patient weight and

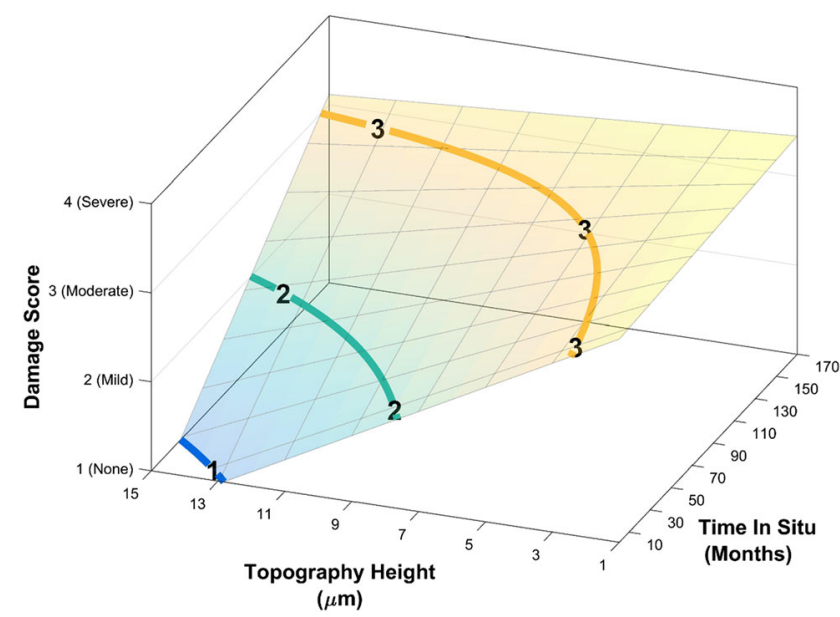

Fig. 6 Regression model shows stem taper damage scores for $\mathrm{CoCr} /$ $\mathrm{CoCr}$ couples as a function of stem taper machining mark height and time in situ.

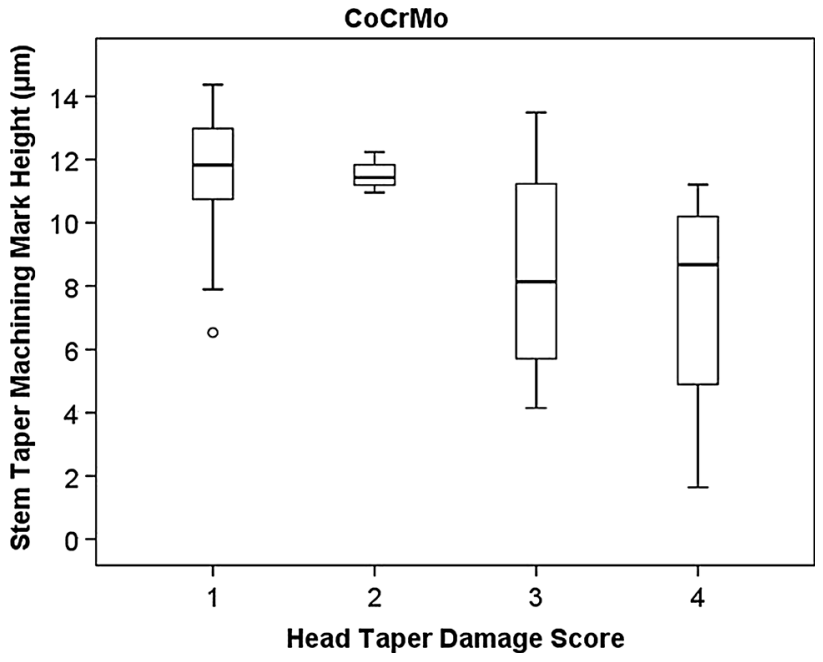

Fig. 7 The relationship between head taper damage score and stem taper machining mark height for $\mathrm{CoCr} / \mathrm{CoCr}$ couples is shown. The circle marks a mild outlier.

implant alignment are additional contributors to taper damage, but those clinical data were not available for this study. Methodological limitations include the use of the semiquantitative damage grading (modified Goldberg score) and the method used to measure stem and head taper angles. A previous study showed that the visual-based Goldberg scoring system was positively correlated to volume loss [20]. For components with severe damage (score 4), there was a broad range of material loss. Therefore, future studies should include both stem tapers of damage score 4 and quantitative analysis of material removed resulting from corrosion and fretting to determine the relationship between the most severely damaged stem tapers and surface topography. The evaluation of stem and 


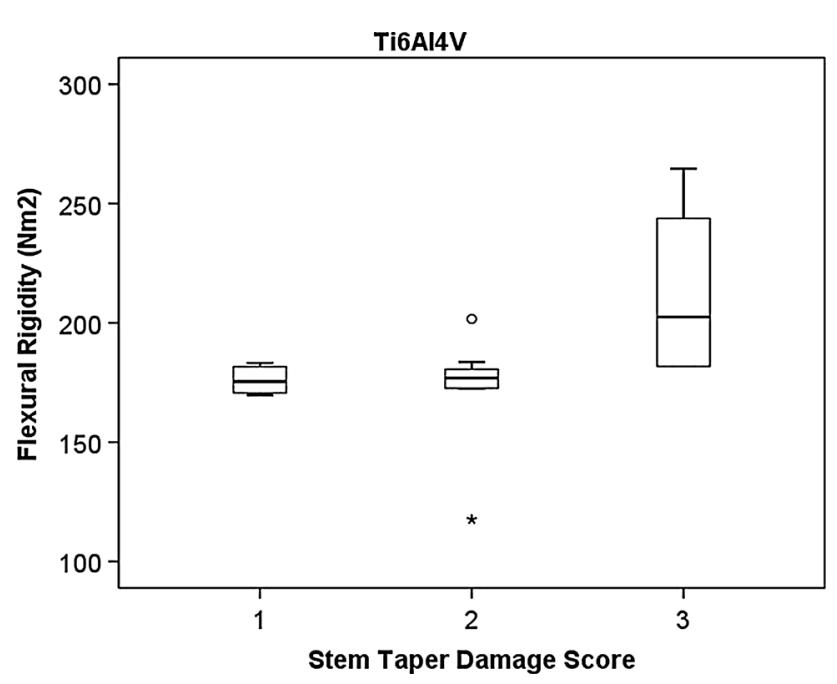

Fig. 8 The relationship between stem taper damage score and flexural rigidity for $\mathrm{CoCr} / \mathrm{Ti}$ couples is shown. The circle marks a mild outlier and the asterisk marks an extreme outlier.

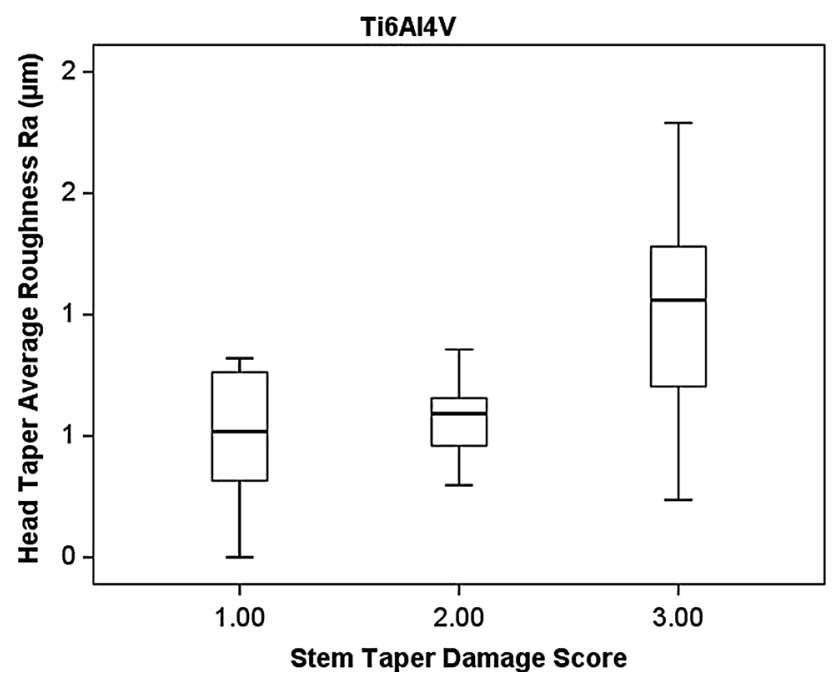

Fig. 9 The relationship between stem taper damage score and head taper roughness for $\mathrm{CoCr} / \mathrm{Ti}$ couples is shown.

head taper angles was based on only 15 points taken in obviously undamaged areas. Other studies have used full metrology data sets to fit the initial taper geometry and to determine the taper angle $[7,8,23]$. However, the obtained results fit well within the range of these studies.

It was our goal to determine differences in damage score and surface topography for the modular junction material couples that were most common in our retrieval repository: $\mathrm{CoCr} / \mathrm{CoCr}$ and $\mathrm{CoCr} / \mathrm{Ti}$. Interestingly, the average damage scores of stem and head tapers were very similar between the two material couples. The main difference was the higher number of severely damaged stem tapers for
$\mathrm{CoCr} / \mathrm{CoCr}$ couples. The reason for more distinct damage is the higher susceptibility of CoCrMo alloy to corrosion under specific circumstances. Earlier studies have shown that different modes of corrosion can occur such as grain and phase boundary corrosion, etching, fretting corrosion, and pitting $[14,15,19]$. Such mechanisms are known to cause severe damage and elevated material loss. Under damage scores 1 to 3 , damage is more mechanically driven (cyclic creep, plastic deformation, mechanically dominated fretting). Interestingly, the occurrence of severe damage to head tapers appears to be independent of the counter alloy. With regard to surface topography, there appears to be no difference between $\mathrm{CoCr}$ and $\mathrm{Ti6Al4V}$ tapers. The machining mark height and spacing are almost identical, indicating that similar machining parameters have been applied. Other studies have reported values for head and stem taper topographies that fit well within our results $[18,23,30,34,39,40]$.

Stem taper machining mark height was associated with greater stem and head taper damage scores after controlling for time in situ, flexural rigidity, taper angle mismatch, head taper roughness, and stem taper machining mark spacing for $\mathrm{CoCr} / \mathrm{CoCr}$ modular junction couples. Interestingly, we were able to show that a gradual increase in damage score over time occurred on stem tapers with higher machining marks, whereas a smoother topography resulted in elevated damage independent of time. Also, the stem taper topography appears to directly impact damage on the head taper side. One study presented results in disagreement with our data [1]. However, they did not consider machining mark height as a continuous variable but rather distinguished between a smooth and rough category. Another study found that rougher and shorter tapers had more taper wear in a large-head metal-on metal system [3]. Again, surface topography was characterized by average roughness, not machining mark height. Our own work based on multiscale finite element analysis supports our results that surface topography plays a meaningful role in damage evolution of modular junction [27]. The surface topography drives the actual and real contact area, the degree of plastic strain, and residual stresses. Interestingly, we did not find that flexural rigidity was associated with stem taper damage score within different material couples, although a previous study found that necks with higher flexural rigidity exhibited lower damage scores [17]. However, this study did not use a multiple regression model that takes other factors into account.

Although there was no difference in surface topography between the two material couples, unlike $\mathrm{CoCr}$ stem tapers, Ti6Al4V stem tapers exhibited a damage evolution that was independent of implantation time. In the multiple regression model, damage score did correlate with stem taper machining mark height and head taper roughness. 
Both factors drive the contact area and contact mechanics between the two surfaces. However, it needs to be stated that the initial head taper roughness could not be measured with the same certainty as the stem taper topography because a tactile profilometer had to be used instead of the interferometer. As a result of the lack of optical feedback of measuring, it was more challenging to exclude damaged areas. Thus, it is possible that the head taper roughness, which increases with damage score, is partly a result of head taper damage rather than a contributing factor. The reason for this manifesting noticeably in the $\mathrm{CoCr} / \mathrm{Ti}$ couple may be related to the occurrence of material transfer from the softer Ti6Al4V alloy to the CoCrMo alloy. Such material transfer is the result of microjoints (cold welding) that may already have formed during the initial assembly or resulted from cyclic load. Potentially, the actual material transfer did not occur until separation of the head and stem. Material transfer would be detected by visual inspection as damage, but can only be distinguished from corrosion damage by scanning electron microscopy (Fig. 10), which may explain the higher proportion of moderately damaged head tapers for $\mathrm{CoCr} / \mathrm{Ti}$ (Table 3). However, the stem taper topography would still play an important role because it is directly related to the local contact stresses necessary for the formation of microjoints and subsequent material transfer. Currently, it is unclear whether material transfer is harmful by increasing two-body wear or useful by preventing micromotion.

In conclusion, we were able to show that stem taper machining mark height plays a crucial role in modular junction performance, especially for $\mathrm{CoCr} / \mathrm{CoCr}$ couples, where a higher stem taper machining mark height results in lower damage score over implantation time. Surface

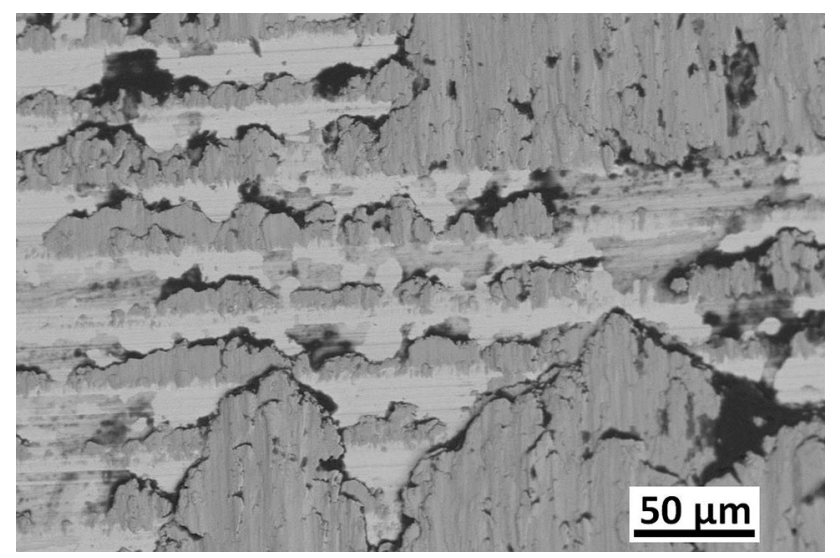

Fig. 10 Scanning electron micrograph of a $\mathrm{CoCr} / \mathrm{Ti}$ head taper surface showing an example of titanium transfer to CoCrMo. The image was taken in backscatter mode where dark areas represent titanium transfer and brighter areas represent the underlying CoCrMo alloy. topography appears to also impact damage modes of $\mathrm{CoCr}$ / $\mathrm{Ti}$ couples; however, this interface deserves further investigation. It is of great importance to determine the acting damage modes (corrosion, wear, plastic deformation) and how they relate to damage score and material loss to better understand the role of surface topography. It needs to be stated that other design factors (such as engagement length), patient factors (eg, patient weight), and surgeon factors (eg, implant alignment) may play an important role, although they could not be considered in this study. Nonetheless, based on the results of this study, we believe that the accepted dimensions and tolerances of stem taper surface topographies need further attention to ensure that damage is minimized within each material couple. We expect that surface topography characteristics can be adjusted during machining to reduce the degree of damage, delay the onset of corrosion, and to reduce the release of corrosion products.

Acknowledgments We thank Richard Eenigenburg, Erica Dahlmeier MPH, Jennifer Wright MS, and Stephanie McCarthy BS for assistance with data collection. Hajwa Kim MS, provided statistical assistance through the Center for Clinical and Translational Science, University of Illinois at Chicago. We also thank Drs Nadim Hallab, Michel Laurent, and Markus Wimmer for technical assistance and valuable insights.

\section{References}

1. Arnholt C, Underwood R, MacDonald DW, Higgs GB, Chen AF, Klein G, Hamlin B, Lee G-C, Mont M, Cates H, Malkani A, Kraay M, Rimnac C, Kurtz SM. Microgrooved surface topography does not influence fretting corrosion of tapers in total hip arthroplasty: classification and retrieval analysis. In: Greenwald AS, Kurtz SM, Lemons JE, Mihalko WM, eds. Modularity and Tapers in Total Joint Replacement Devices. ASTM STP1591. West Conshohocken, PA, USA: ASTM International; 2015:99_ 112.

2. Bisseling P, Tan T, Lu Z, Campbell PA, Van Susante JLC. The absence of a metal-on-metal bearing does not preclude the formation of a destructive pseudotumor in the hip-a case report. Acta Orthop. 2013;84:437-441.

3. Brock TM, Sidaginamale R, Rushton S, Nargol AVF, Bowsher JG, Savisaar C, Joyce TJ, Deehan DJ, Lord JK, Langton DJ. Shorter, rough trunnion surfaces are associated with higher taper wear rates than longer, smooth trunnion surfaces in a contemporary large head metal-on-metal total hip arthroplasty system. $J$ Orthop Res. 2015;33:1868-1874.

4. Brown SA, Flemming CAC, Kawalec JS, Placko HE, Vassaux C, Merritt K, Payer JH, Kraay MJ. Fretting corrosion accelerates crevice corrosion of modular hip tapers. J Appl Biomater. 1995;6:19-26.

5. Burroughs BR, Muratoglu OK, Bragdon CR, Wannomae KK, Christensen S, Lozynsky AJ, Harris WH. In vitro comparison of frictional torque and torsional resistance of aged conventional gamma-in-nitrogen sterilized polyethylene versus aged highly crosslinked polyethylene articulating against head sizes larger than $32 \mathrm{~mm}$. Acta Orthop. 2006;77:710-718.

6. Chana R, Esposito C, Campbell PA, Walter WK, Walter WL. Mixing and matching causing taper wear: corrosion associated 
with pseudotumour formation. J Bone Joint Surg Br. 2012;94: 281-286.

7. Cook RB, Bolland BJRF, Wharton JA, Tilley S, Latham JM, Wood RJK. Pseudotumour formation due to tribocorrosion at the taper interface of large diameter metal on polymer modular total hip replacements. J Arthroplasty. 2013;28:1430-1436.

8. Cook RB, Maul C, Strickland AM. Validation of an optical coordinate measuring machine for the measurement of wear at the taper interface in total hip replacement. In: Greenwald AS, Kurtz SM, Lemons JE, Mihalko WM, eds. Modularity and Tapers in Total Joint Replacement Devices. ASTM STP1591. West Conshohocken, PA, USA: ASTM International; 2015:362378.

9. Cooper HJ, Della Valle CJ, Berger RA, Tetreault M, Paprosky WG, Sporer SM, Jacobs JJ. Corrosion at the head-neck taper as a cause for adverse local tissue reactions after total hip arthroplasty. J Bone Joint Surg Am. 2012;94:1655-1661.

10. Cooper HJ, Della Valle CJ, Jacobs JJ. Biologic implications of taper corrosion in total hip arthroplasty. Semin Arthroplasty. 2012;23:273-278.

11. Doehring TC, Rubash HE, Dore DE. Micromotion measurements with hip center and modular neck length alterations. Clin Orthop Relat Res. 1999;362:230-239.

12. Dyrkacz RMR, Brandt J-M, Ojo OA, Turgeon TR, Wyss UP. The influence of head size on corrosion and fretting behaviour at the head-neck interface of artificial hip joints. $J$ Arthroplasty. 2013;28:1036-1040.

13. Garbuz DS, Tanzer M, Greidanus NV, Masri BA, Duncan CP. The John Charnley Award: Metal-on-metal hip resurfacing versus large-diameter head metal-on-metal total hip arthroplasty: a randomized clinical trial. Clin Orthop Relat Res. 2010;468:318325.

14. Gilbert JL, Buckley CA, Jacobs JJ. In vivo corrosion of modular hip prosthesis components in mixed and similar metal combinations. The effect of crevice, stress, motion, and alloy coupling. $J$ Biomed Mater Res. 1993;27:1533-1544.

15. Gilbert JL, Buckley CA, Jacobs JJ, Bertin KC, Zernich MR. Intergranular corrosion-fatigue failure of cobalt-alloy femoral stems. A failure analysis of two implants. J Bone Joint Surg Am. 1994;76:110-115.

16. Gilbert JL, Mehta M, Pinder B. Fretting crevice corrosion of stainless steel stem-CoCr femoral head connections: comparisons of materials, initial moisture, and offset length. J Biomed Mater Res B Appl Biomater. 2009;88:162-173.

17. Goldberg JR, Gilbert JL, Jacobs JJ, Bauer TW, Paprosky W, Leurgans S. A multicenter retrieval study of the taper interfaces of modular hip prostheses. Clin Orthop Relat Res. 2002;401:149-161.

18. Hallab NJ, Messina C, Skipor A, Jacobs JJ. Differences in the fretting corrosion of metal-metal and ceramic-metal modular junctions of total hip replacements. J Orthop Res. 2004;22:250 259.

19. Hall DJ, Pourzal R, Della Valle CJ, Galante JO, Jacobs JJ, Urban RM. Corrosion of modular junctions in femoral and acetabular components for hip arthroplasty and its local and systemic effects. In: Greenwald AS, Kurtz SM, Lemons JE, Mihalko WM, eds. Modularity and Tapers in Total Joint Replacement Devices. ASTM STP1591. West Conshohocken, PA, USA: ASTM International; 2015:410-427.

20. Hothi HS, Matthies AK, Berber R, Whittaker RK, Skinner JA, Hart AJ. The reliability of a scoring system for corrosion and fretting, and its relationship to material loss of tapered, modular junctions of retrieved hip implants. J Arthroplasty. 2014;29: 1313-1317.

21. Jauch SY, Huber G, Hoenig E, Baxmann M, Grupp TM, Morlock MM. Influence of material coupling and assembly condition on the magnitude of micromotion at the stem-neck interface of a modular hip endoprosthesis. J Biomech. 2011;44:1747-1751.

22. Johnson AJ, Le Duff MJ, Yoon JP, Al-Hamad M, Amstutz HC. Metal ion levels in total hip arthroplasty versus hip resurfacing. $J$ Arthroplasty. 2013;28:1235-1237.

23. Kocagöz SB, Underwood RJ, Sivan S, Gilbert JL, MacDonald DW, Day JS, Kurtz SM. Does taper angle clearance influence fretting and corrosion damage at the head-stem interface? A matched cohort retrieval study. Semin Arthroplasty. 2013;24:246-254.

24. Langton DJ, Sidaginamale R, Lord JK. Taper junction failure in large-diameter metal-on-metal bearings. Bone Joint Res. 2012;1: 56-63.

25. Lavigne M, Belzile EL, Roy A, Morin F, Amzica T, Vendittoli PA. Comparison of whole-blood metal ion levels in four types of metal-on-metal large-diameter femoral head total hip arthroplasty: the potential influence of the adapter sleeve. $J$ Bone Joint Surg Am. 2011;93:128-136.

26. Lindgren JU, Brismar BH, Wikstrom AC. Adverse reaction to metal release from a modular metal-on-polyethylene hip prosthesis. J Bone Joint Surg Br. 2011;93:1427-1430.

27. Lundberg HJ, Ha NQ, Hall DJ, Urban RM, Levine BR, Pourzal R. Contact mechanics and plastic deformation at the local surface topography level after assembly of modular head-neck junctions in modern total hip replacement devices. In: Greenwald AS, Kurtz SM, Lemons JE, Mihalko WM, eds. Modularity and Tapers in Total Joint Replacement Devices. ASTM STP1591. West Conshohocken, PA, USA: ASTM International; 2015:59-82.

28. Mao X, Tay GH, Godbolt DB, Crawford RW. Pseudotumor in a well-fixed metal-on-polyethylene uncemented hip arthroplasty. $J$ Arthroplasty. 2012;27:493.e13-493.e17.

29. Meftaha M, Nicolaoub N, Rodriguezc JA. Metal allergy response to femoral head-neck corrosion after total hip replacement. Curr Orthop Pract. 2010;21:530-533.

30. Munir S, Cross MB, Esposito C, Sokolova A, Walter WL. Corrosion in modular total hip replacements: an analysis of the headneck and stem-sleeve taper connections. Semin Arthroplasty. 2013;24:240-245.

31. Porter DA, Urban RM, Jacobs JJ, Gilbert JL, Rodriguez JA, Cooper HJ. Modern trunnions are more flexible: a mechanical analysis of THA taper designs. Clin Orthop Relat Res. 2014;472:3963-3970.

32. Rehmer A, Bishop NE, Morlock MM. Influence of assembly procedure and material combination on the strength of the taper connection at the head-neck junction of modular hip endoprostheses. Clin Biomech. 2012;27:77-83.

33. Svensson O, Mathiesen EB, Reinholt FP, Blomgren G. Formation of a fulminant soft-tissue pseudotumor after uncemented hip arthroplasty. A case report. J Bone Joint Surg Am. 1988;70:12381242.

34. Underwood RJ, Kocagoz SB, Smith R, Sayles RS, Siskey R, Kurtz SM, Cann PM. A protocol to assess the wear of head/neck taper junctions in large head metal-on-metal (LHMoM) hips. In: Kurtz SM, Greenwald AS, Mihalko WM, Lemons JE, eds. Metal-on-metal Total Hip Replacement Devices. ASTM STP1560. West Conshohocken, PA, USA: ASTM International; 2013:209-234.

35. Urban RM, Hall DJ, Gilbert JL, Dahlmeier EL, Wright JL, Della Valle CJ, Galante JO, Jacobs JJ. Are fretting and corrosion reduced in contemporary head/neck modular junctions? Trans ORS. 2012:1050. Available at: http://www.ors.org/Transactions/ 58/1050.pdf. Accessed May 1, 2016.

36. Vendittoli P-A, Amzica T, Roy AG, Lusignan D, Girard J, Lavigne M. Metal ion release with large-diameter metal-on-metal hip arthroplasty. J Arthroplasty. 2011;26:282-288. 
37. Walsh AJ, Nikolaou VS, Antoniou J. Inflammatory pseudotumor complicating metal-on-highly cross-linked polyethylene total hip arthroplasty. J Arthroplasty. 2012;27:324.e5-324.e8.

38. Watanabe H, Takahashi K, Takenouchi K, Sato A, Kawaji H, Nakamura H, Takai S. Pseudotumor and deep venous thrombosis due to crevice corrosion of the head-neck junction in metal-on-polyethylene total hip arthroplasty. J Orthop Sci. 2015;20:1142-1147.
39. Witt F, Gührs J, Morlock MM, Bishop NE. Quantification of the contact area at the head-stem taper interface of modular hip prostheses. PLoS One. 2015;10:e0135517.

40. Zhang T, Harrison NM, McDonnell PF, McHugh PE, Leen SB. Micro-macro wear-fatigue of modular hip implant taper-lock coupling. J Strain Anal Eng Des. 2014; 49:2-18. 